\title{
Self-medication among Undergraduate Medical Students of Alexandria Faculty of Medicine: Where do We Stand?
}

\author{
Marwa Ramadan, Asmaa Eltaweel, Tamwe El Nakhal, Hanan Hemead, Abdelrahman Maraqa, Doha Abish, Rana Essam, Azza Baraka. ${ }^{1}$
}

\begin{abstract}
Background: The aim of the present study was to assess the prevalence of self-medication among undergraduate medical students in Alexandria Faculty of Medicine and recognize the patterns and the attitude of students towards intake. Methods: A cross-sectional study was conducted among undergraduate medical students attending Alexandria Faculty of Medicine from both national and international programs during the period of June 2013 until $0 \mathrm{ctober}$ 2013. A self-administrated, semi-constructed questionnaire was used to assess the practice of self-medication among 408 students who were randomly selected using a stratified random sample technique. Results: Self-medication was reported by $208(52.7 \%)$ students, with no significant difference between males and females. The highest percentage of self-medication was reported among those who have completed six years of academic study and the lowest was reported among those who have completed two years of academic study. There was a statistically significant association between educational stage (preclinical and clinical) practice of self-medication. Most common medications involved were analgesic and anti-inflammatory followed by decongestants, antimicrobials and antihistaminic drugs. 309 (78.8\%) students believed that self-medication is acceptable. Conclusion: The present study demonstrated that self-medication is practiced by more than half of undergraduate medical students in the Faculty of Medicine - Alexandria University. Acquiring medical knowledge seems to be associated with the practice of self-medication. Therefore, more attention should be paid to medical curricula to raise awareness and limit the hazardous effects of this phenomenon.
\end{abstract}

Key Words: Self-Medications; OTC Drugs; Non-Prescription Drugs; Medical Students; Egypt (Source: MeSH-NLM).

\section{Introduction}

Self-medication has been defined as the use of medicinal products for treating self-recognized disorders, as well as regular or irregular use of medications prescribed for chronic, recurrent diseases or symptoms. Practically, it may also include the use of medications for treating children or elder family members. ${ }^{1}$ There is an international growing concern on how medical personnel deal with their own health problems since it will not only have negative impacts on physicians but also their patients. In addition, self-medication compromises the efficiency of medical system and the delivery of professional medical care.2-4 Previous research revealed numerous disadvantages of self-medication including pathogen resistance, adverse drug effects, drug dependence as well as economic burden..$^{-8}$

Self-medication prevalence has been globally discussed in previous studies. In Europe it may reach up to $68 \% .9$ On the other hand, the prevalence is dramatically higher in developing countries. ${ }^{10}$ In Karachi, it is about $76 \%$, and around $92 \%$ in Kuwait among adolescents. ${ }^{11-12}$ In a recent review, the prevalence of antimicrobial self-medication in the Middle East ranged from $19 \%$ to $82 \%$, reflecting difference in study designs and contextual factors. ${ }^{13}$ Self-medication is of particular concern especially in the less developed countries due to the availability of medications with absence of rules and regulations that prohibit such practice. ${ }^{14-15}$

According to the World Health Organization, self-medication could be practiced only in minor troublesome conditions provided that the drug shows acceptable safety and efficacy considering its dose and duration. ${ }^{1}$ However, increased costs of medical consultation in developing countries combined with dissatisfaction with medical practitioners has augmented the problem. ${ }^{16}$
Medical students experience great psychological burden due to the nature of their study combined with unrestricted access to pharmaceuticals. These burdens may increase the chance of drug misuse. ${ }^{17-18}$ Due to complexity of self-referral and shortage of time, medical students may deal irrationally with their conditions and prefer to use a drug recommended by their colleagues. Studies have reported high prevalence of self-medication among medical students ranging from $57.7 \%$ to $76 \% .19-20$ There is paucity of research concerning this phenomenon in the Middle East. On the national level, it seems that only two studies were conducted in Ain Shams University and Mansoura universities, with a prevalence of self-medication of $79.9 \%$ and $62.9 \%$ respectively. ${ }^{21-22}$ Further studies are required to determine extent and reasons of such practice and whether it was common among medical students in various governorates in Egypt. Therefore, the aim of the present study was to assess the prevalence of self-medication among undergraduate medical students in Alexandria and recognize the patterns and the attitude of students towards intake.

\section{Methods}

A cross-sectional study was conducted among undergraduate medical students attending Alexandria Faculty of Medicine from both national and international programs during the period of June 2013 until October 2013. All grades from $1^{\text {st }}$ to $6^{\text {th }}$ year were included in the study. A crosssectional design was selected since responses were anonymous and it was not feasible to track self-medication patterns in a longitudinal design. The study was approved by the Ethics Committee of Alexandria Faculty of Medicine in May 2012.

A sample size of 360 was estimated using Epi Info 7 with the addition of $15 \%$ to account for losses giving a total sample size of 408 students. Sample size was calculated based on $95 \%$ confidence interval and a

\footnotetext{
${ }^{1}$ Faculty of Medicine, Alexandria University, Alexandria Governorate, Egypt.
}

About the Author: Marwa Ramadan is working as Assistant Lecturer of Occupational Health at the Department of Community Medicine and Public Health at the Faculty of Medicine, Alexandria University, Egypt. 
prevalence rate of $55 \%$ as reported by a previous national study. ${ }^{21}$ To ensure the representation of all educational grades, subjects were selected using a stratified random sample of students from the first to the sixth year with proportion allocation. The purpose of the study was explained, and verbal consent was obtained before the distribution of questionnaires. Data were collected using a self-administrated, semiconstructed questionnaire to assess the practice of self-medication as the main outcome variable among the studied participants. The questionnaire included three main sections; the first section involved socio-demographic data as age, gender and educational stage; the second section included questions related to the practice of selfmedication, common reasons, medication categories, common illnesses and symptoms involved; and the third section included questions related to participants' opinion towards self-medication, its advantages and disadvantages and the change in the participants' practice while acquiring medical knowledge.

\section{Statistical analysis}

Data were analyzed using SPSS version 20, descriptive statistics were estimated for variables as medication categories, reasons behind selfmedication and associated illnesses. Chi-square test was used to test the significance of association between the practice of self-medication as the main outcome variable and independent variables as gender, associated symptoms and educational stage.

\section{Results}

Out of 408 students, $395(98.1 \%)$ responded to the questionnaire of which $162(41 \%)$ were males and $233(59 \%)$ were females. Table I shows demographic characteristics of participants. Self-medication was reported by 208 students (52.7\%) with no significant difference between males and females $(p=0.086)$. Highest proportion of self-medication $(67.3 \%)$ was reported among those who have completed six years of academic study and the lowest was reported among those who have completed two years of academic study (40.4\%). There was a statistically significant association between educational stage (preclinical and clinical) and practice of self-medication $(\mathrm{p}=0.048)$.

Table 1. Demographic Characteristics of the Studied Sample of Undergraduate Medical Students of Alexandria Faculty of Medicine, Egypt $(\mathrm{N}=395)$.

\begin{tabular}{|c|c|c|c|c|c|c|}
\hline 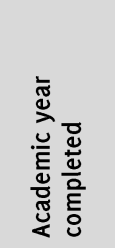 & 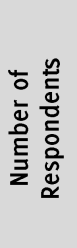 & $\frac{\mathscr{N}}{2}$ & 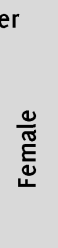 & 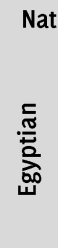 & 늘 & 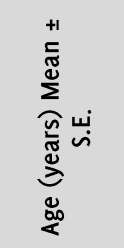 \\
\hline $\begin{array}{l}\text { Fresh } \\
\text { students }\end{array}$ & 42 & 13 & 40 & 40 & 2 & $18.26 \pm 0.08$ \\
\hline First Year & 89 & 44 & 78 & 78 & 11 & $18.91 \pm 0.09$ \\
\hline $\begin{array}{l}\text { Second } \\
\text { Year }\end{array}$ & 52 & 20 & 50 & 50 & 2 & $19.73 \pm 0.10$ \\
\hline $\begin{array}{l}\text { Third } \\
\text { Year }\end{array}$ & 26 & 17 & 16 & 16 & 10 & $21.00 \pm 0.10$ \\
\hline $\begin{array}{l}\text { Fourth } \\
\text { Year }\end{array}$ & 74 & 20 & 71 & 71 & 3 & $21.14 \pm 0.13$ \\
\hline Fifth Year & 60 & 33 & 59 & 59 & 1 & $22.03 \pm 0.09$ \\
\hline $\begin{array}{l}\text { Sixth } \\
\text { Year }\end{array}$ & 52 & 15 & 49 & 49 & 3 & $22.98 \pm 0.10$ \\
\hline Total & 395 & 162 & 233 & 363 & 32 & $20.51 \pm 0.88$ \\
\hline
\end{tabular}

Most common medications involved were analgesic and antiinflammatory ( $77 \%$ of respondents, $n=304$ ) followed by decongestants ( $33.4 \%$ of respondents, $n=132$ ), antimicrobials ( $33.1 \%, n=131)$ and antihistaminic ( $33 \%$ of respondents, $n=132$ ).
With respect to associated symptoms, self-medication was frequently reported with chest symptoms ( $78.9 \%$ of cases), followed by headache and neurological symptoms ( $58.4 \%$ of cases), abdominopelvic ( $27 \%$ of cases), general symptoms ( $23.5 \%$ of cases), gastrointestinal ( $20 \%$ of cases) with no statistically significant difference between male and female students except for abdominopelvic symptoms $(p=0.029)$. Figure 1 shows distribution of associated symptoms according to frequency of responses.

Figure 1. Symptoms accompanied with Self-medication among the Studied Sample of Undergraduate Medical Students of Alexandria Faculty of Medicine, Egypt.

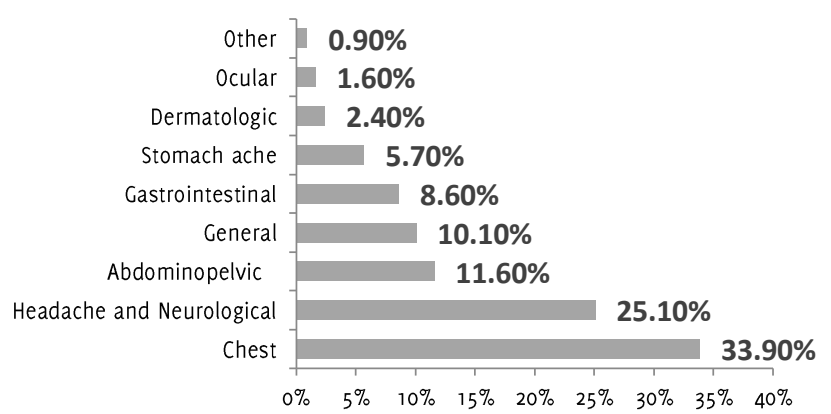

Self-medication was considered acceptable by 309 students (78.8\%). The most commonly reported advantages were: saving time (36.3\%), providing quick relief $(22.5 \%)$ and the ease of use (17.5\%) (Figure 2). Up to $84 \%$ of medical students would continue self-medication for up to one week without improvement in their conditions and only $18 \%$ of students have experienced side effects in association with selfmedication. Students believed that the main disadvantages of selfmedications are misdiagnosis (30\%) and drug resistance (18\%) (Figure 2).

Figure 2. The (A) Advantages and (B) Disadvantages of Self-Medication Reported by the Studied Sample of Undergraduate Medical Students of Alexandria Faculty of Medicine, Egypt.
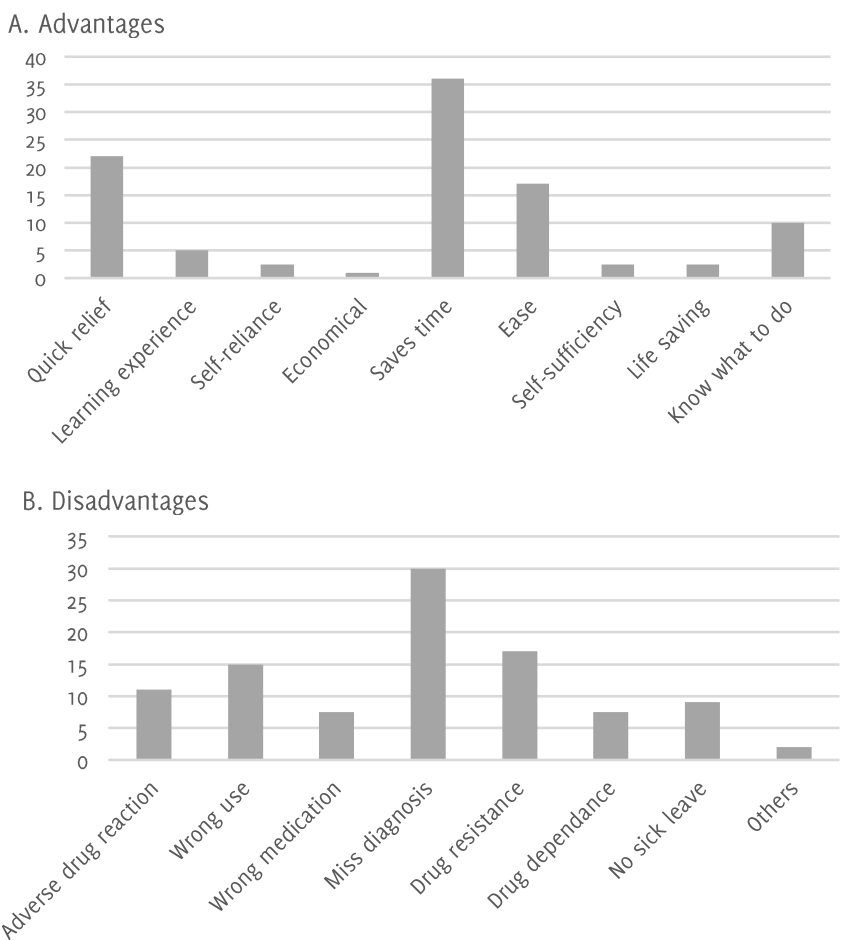
Among many factors that contribute to self-medication, the most frequent were: presence of mild illness $(52 \%)$, previous experience (39\%) paucity of time $(17 \%)$. Only $10 \%$ of students reported that there was no change in self-medication practice habits while acquiring medical knowledge while (45\%) have become more careful, $27 \%$ of students would prefer getting the prescription from a doctor, $25 \%$ would discourage self-medication and $23 \%$ became afraid of adverse effects.

\section{Discussion}

More than half of the studied participants reported self-medication. Such practice increased while acquiring medical knowledge and did not differ according to gender. In addition, analgesic and anti-inflammatory drugs were the most common medication category associated with such practice.

Similar to what has been reported globally, the present study showed that self-medication is widely practiced among medical students $(52.7$ $\%$ ). This is similar to what was reported by two national studies: a recent study among university students in Mansoura University reported a prevalence of $62.9 \%$, and another study among medical students in Ain Shams University reported a prevalence of $55 \%$. 21-22 Our findings are also consistent with what have been described in previous study conducted in India, where the prevalence of selfmedication was 57.5\%.23 Another study conducted in Bahrain showed a prevalence of $44.8 \%$, and in Karachi it was as high as $76 \% . .^{5-18}$ There was no statistically significant difference between male and female students $(p=0.086)$ regarding self-medication which is similar to what have been reported in Slovenia, while differs from what have been demonstrated in a previous study in India. ${ }^{23-24}$

Acquiring medical knowledge and clinical skills had a demonstrable effect on practice of self-medication with the highest frequency was reported by senior students who have completed six years of academic study with statistically significant association between educational stage (preclinical and clinical) and practice of self-medication ( $p=0.048$. In Mansoura University, $62 \%$ reported acquiring knowledge made them safer in practicing self-medication. ${ }^{22}$ These results are also congruent with study conducted among undergraduate medical students in West Bengal where final-year students practiced self-medication more frequently than first-year students ( $p$-value<0.001).23-24

In the present study, self-medication was commonly associated with analgesic and anti-inflammatory drugs (77\%) followed by decongestants $(33.4 \%)$, antimicrobials $(33.1 \%)$ and antihistaminic ( $33 \%)$. This is consistent with the study conducted in Karachi, where analgesics were the most common (88.3\%) followed by antipyretics and antibiotics and the study in Bahrain also reported analgesics to be the most commonly used drug groups (81.3\%).5,20 The frequent use of these drugs for self-medication reflects their availability as over the counter (OTC) medications with absence of rules and regulation that prohibit such practice in the developing countries. 25

Regarding associated symptoms, chest symptoms ( $74.2 \%$ ), followed by headache and neurological symptoms (54.9\%), abdominopelvic (25\%) were the most frequently reported at Mansoura University where cold was the most frequent symptom (70.1\%), and followed by headache $(58.9 \%)$, sore throat $(35.8 \%)$ and intestinal colic $(32.2 \%) .22$ In the study conducted in West Bengal, cough/common cold (35.21\%) were the most frequent, followed by diarrhea, fever, and headache.23

In Bahrain, first year medical students reported headache as the most frequent symptom (70.9\%), followed by cough/common cold, stomachache, and fever. 5 There was no gender related difference regarding self-medication associated symptoms except for the abdominopelvic $(p=0.029)$, which may reflect tendency of females to self-medicate for menstrual symptoms.
The majority of students (78.8\%) believed that self-medication is acceptable and they rationalized it due to time savings (36.3\%), quick relief of symptoms $(22.5 \%)$ and ease of use $(17.5 \%)$. Consistently, the national study at Ain Shams University showed that (56.5\%) of medical students reported that taking drugs without medical prescription was no problem and another study conducted in India showed that $70 \%$ students favored self-medication and the most common disadvantages were time saving $(41.2 \%)$, followed by convenience $(39.6 \%)$, quick relief $(35.5 \%)$ and cost-effectiveness (22.8\%).21.26 In addition, the present study found that $84 \%$ may even continue to self-medicate for up to one week without improvement in their conditions. With respect to adverse effects, only $18 \%$ of students have experienced side effects in association with self-medication. In addition, students reported that self-medication could lead to are misdiagnosis (30\%) and drug resistance $(18 \%)$. In the study conducted in India, $70.8 \%$ of students were aware of adverse reactions of drugs used for self-medication, and $7.6 \%$ students had experienced it. 26

The present study found that presence of mild illness $(52 \%)$, previous experience $(39 \%)$ paucity of time $(17 \%)$ were the most frequent reasons behind self-medication. In Mansoura University, the most frequent cause of self-medication was no need to visit the doctor for minor illness ( $74 \%$ ), followed by previous experience and knowledge ( $71 \%)$, and lastly unavailability of health services. ${ }^{22}$ The difference the frequency and some causes between this study and Mansoura University may be due to difference in study population since the later involved both medical and non-medical students reflecting a general practice in a university serving a large rural community. Similar findings were reported by undergraduate medical students in a tertiary care medical college in West Bengal, where mild nature of illness was the most common symptom (47.19\%) and in Bahrain $45.5 \%$ of students preferred self-medication as it is time-saving while $25.4 \%$ preferred it due to minor nature of illness. $19,2345 \%$ of students reported that while acquiring medical knowledge, they became more careful, $27 \%$ preferred getting the prescription from a doctor, $25 \%$ discouraged selfmedication and $23 \%$ became afraid of adverse effects, an effect which could be demonstrated by the presence of lowest frequency of selfmedication among those who have completed three years of academic study $(40.4 \%)$ coinciding with studying pharmacology curriculum. The later increase in the tendency towards self-medication among senior students (those who have completed six years of academic study) (63.7\%) could be explained by gaining confidence of self-prescription after finishing undergraduate medical education and preparing for their internship. These results are also similar to what have been reported in Bahrain, where senior students practiced self-medication more often and with more confidence. 19

This study is the first to assess the prevalence of self-medication among undergraduate medical students in Alexandria Faculty of Medicine since data were collected from all six undergraduate years using a stratified random sampling methodology. On the other hand, the main limitation of the present study is the lack of generalizability to represent all undergraduate medical students in Egypt since students enrolled in Alexandria Faculty of Medicine are mainly from four governorates: Alexandria, Behira, Kafr-Elsheikh and Matrouh. Thus, a multi-centric study involving different governorates will be more valuable.

The present study demonstrated that self-medication is widely practiced among undergraduate medical students in Faculty of Medicine - Alexandria University. With the absence of guiding rules and regulations in less developed countries, more attention should be paid to undergraduate medical curricula to raise awareness and limit the hazardous effects of this phenomenon, not only contributing to the health of medical professions, but also their communities. 


\section{References}

1. World Health Organization. Guidelines for the regulatory assessment of medicinal products for use in self-medication. 2000.

2. Asubonteng Rivers $P$, Bae S. Substance abuse and dependence in physicians: detection and treatment. Health Manpow Manage. 1998;24(5):183-187.

3. Leape LL, Fromson JA. Problem doctors: is there a system-level solution? Ann Intern Med. 2006;144(2):107-115.

4. Bohigian GM, Croughan JL, Sanders K. Substance abuse and dependence in physicians: an overview of the effects of alcohol and drug abuse. Mo Med. 1994 May;91(5):233-239.

5. James H, Handu SS, Al Khaja KA, Otoom S, Sequeira RP. Evaluation of the knowledge, attitude and practice of self-medication among first-year medical students. Med Princ Pract. 2006;15(4):270-275.

6. Kiyingi K, Lauwo J. Drugs in the home: danger and waste. 1993.

7. Hughes CM, MCElnay JC, Fleming CF. Benefits and risks of self medication. Drug Safety. 2001;24(14):1027-1037.

8. Hem E, Stokke G, Tyssen R, Grønvold NT, Vaglum P, Ekeberg $\emptyset$. Self-prescribing among young Norwegian doctors: a nine-year follow-up study of a nationwide sample. BMC Medicine. 2005;3(1):16.

9. Bretagne JF, Richard-Molard B, Honnorat C, Caekaert A, Barthelemy P. Castroesophageal reflux in the French general population: national survey of 8000 adults. Presse Med. 2006 Jan;35(1 Pt 1):23-31.

10. Shankar $P$, Partha $P$, Shenoy N. Self-medication and non-doctor prescription practices in Pokhara valley, Western Nepal: a questionnaire-based study. BMC Fam Pract. 2002;3(1):17.

11. Abahussain E, Matowe LK, Nicholls PJ. Self-reported medication use among adolescents in Kuwait. Med Princ Pract. 2005 May-Jun;14(3):161-164.

12. Zafar SN, Syed R, Waqar S, Irani FA, Saleem S. Prescription of medicines by medical students of Karachi, Pakistan: a cross-sectional study. BMC Public Health. 2008;8(1):162.

13. Alhomoud F, Aljamea Z, Almahasnah R, Alkhalifah K, Basalelah L, Alhomoud FK. Self-medication and self-prescription with antibiotics in the Middle East-do they really happen? A systematic review of the prevalence, possible reasons, and outcomes. Int J Infect Dis. 2017 Apr;57:3-12.

14. Byarugaba DK. A view on antimicrobial resistance in developing countries and responsible risk factors. Int J Antimicrob Agents. 2004 Aug;24(2):105-110.
15. Hart CA, Kariuki S. Antimicrobial resistance in developing countries. BMJ. 1998 Sep 5:317(7159):647-650.

16. Grigoryan L, Burgerhof JG, Degener JE, Deschepper R, Lundborg CS, Monnet DL, et al. Determinants of self-medication with antibiotics in Europe: the impact of beliefs, country wealth and the healthcare system. J Antimicrob Chemother. 2008;61(5):11721179 .

17. Chew-Graham CA, Rogers A, Yassin N. 'I wouldn't want it on my CV or their records': medical students' experiences of help-seeking for mental health problems. Med Educ. 2003;37(10):873-880.

18. Roberts LW, Warner TD, Lyketsos C, Frank E, Ganzini L, Carter D. Perceptions of academic vulnerability associated with personal illness: a study of 1,027 students at nine medical schools. Collaborative Research Group on Medical Student Health. Compr Psychiatry. 2001 Jan-Feb;42(1):1-15.

19. James $H$, Handu SS, Khaja KA, Sequeira RP. Influence of medical training on selfmedication by students. Int I Clin Pharmacol Ther. 2008 Jan;46(1):23-29.

20. Zafar SN, Syed R, Waqar S, Zubairi AJ, Vaqar T, Shaikh M, et al. Self-medication amongst university students of Karachi: prevalence, knowledge and attitudes. J Pak Med Assoc. 2008 Apr;58(4):214-7.

21. El Ezz N, Ez-Elarab H. Knowledge, attitude and practice of medical students towards self medication at Ain Shams University, Egypt. J Prev Med Hyg. 2011 Dec;52(4):196-200.

22. Helal R, Abou-EIWafa H. Self-Medication in University Students from the City of Mansoura, Egypt. J Environ Public Health. 2017;2017:9145193.

23. Banerjee I, Bhadury T. Self-medication practice among undergraduate medical students in a tertiary care medical college, West Bengal. J Postgrad Med. 2012;58(2):127. 24. Klemenc-Ketiš Z, Hladnik Ž, Kersnik J. A cross sectional study of sex differences in self-medication practices among university students in Slovenia. Coll Antropol. 2011;35(2):329-334.

25. Bennadi D. Self-medication: A current challenge. J Basic Clin Pharm. 2013 $\operatorname{Dec} ; 5(1): 19-23$

26. Pandya RN, Jhaveri KS, Vyas Fl, Patel V]. Prevalence, pattern and perceptions of self-medication in medical students. Int J Basic Clin Pharmacol. 2013 Jun;2(3):275-280.

\section{Acknowledgments \\ Students of Alexandria Faculty of Medicine who had participated in this study. Conflict of Interest Statement it Funding}

The Authors have no funding, financial relationships or conflicts of interest to disclose.

Author Contributions

Conception and design of the work/idea: AE. Collection of data/obtaining results: AE, TEN, HH, AM, DA, RE. Analysis and interpretation of data: MR, TEN. Writing of the manuscript: $M R, A E, T E N, H H, A M, D A, R E, A B$. Critical revision of the manuscript: $M R, A E, T E N, H H, A M, D A, R E, A B$. Approval of the final version: $M R, A E, T E N, H H, A M, D A, R E, A B$. Statistical advice: MR. Administrative or technical advice: $M R, H H, A B$.

Cite as:

Ramadan M, Eltaweel A, El Nakhal T, Hemead H, Maraqa A, Abish D, Essam R, Baraka A. Self-medication among Undergraduate Medical Students of Alexandria Faculty of Medicine: Where do We Stand?. Int J Med Students. 2018;6(2):52-55.

This work is licensed under a Creative Commons Attribution 4.0 International License 